\title{
Effect of the presence of remnant thyroid tissue on the serum thyroid hormone balance in thyroidectomized patients
}

\author{
Mitsuru Ito, Akira Miyauchi, Shino Kang, Mako Hisakado, Waka Yoshioka, \\ Akane Ide, Takumi Kudo, Eijun Nishihara, Minoru Kihara, Yasuhiro Ito, \\ Kaoru Kobayashi, Akihiro Miya, Shuji Fukata, Hirotoshi Nakamura and \\ Nobuyuki Amino
}

Center for Excellence in Thyroid Care, Kuma Hospital, 8-2-35, Shimoyamate-Dori, Chuo-Ku, Kobe-City, Hyogo 650-0011, Japan
Correspondence should be addressed to $M$ Ito

Email

ito02@kuma-h.or.jp

\begin{abstract}
Objective: We and others recently reported that in total thyroidectomy $(T T)$, serum triiodothyronine $\left(T_{3}\right)$ levels during levothyroxine $\left(\mathrm{L}-\mathrm{T}_{4}\right)$ therapy were low compared to the preoperative levels, suggesting that the presence of the thyroid tissue affects the balances of serum thyroid hormone levels. However, the effects of remnant thyroid tissue on these balances in thyroidectomized patients have not been established.

Methods: We retrospectively studied 253 euthyroid patients with papillary thyroid carcinoma who underwent a TT or hemithyroidectomy (HT). We divided the cases into the TT + supplemental $\mathrm{L}-\mathrm{T}_{4}\left(+\mathrm{L}-\mathrm{T}_{4}\right)$ group $(n=103)$; the HT+ $\mathrm{L}_{4}$ group ( $n=56)$; and the HT-alone group $(n=94)$. We compared the postoperative serum levels of free $\mathrm{T}_{4}\left(\mathrm{FT}_{4}\right)$ and free $\mathrm{T}_{3}\left(\mathrm{FT}_{3}\right)$ and the $\mathrm{FT}_{3} / \mathrm{FT}_{4}$ ratio in individual patients with those of controls matched by serum TSH levels.

Results: The TT+L-T group had significantly higher $\mathrm{FT}_{4}(P<0.001)$, lower $\mathrm{FT}_{3}(P<0.01)$ and lower $\mathrm{FT}_{3} / \mathrm{FT}_{4}(P<0.001)$ levels compared to the controls. The $\mathrm{HT}+\mathrm{L}-\mathrm{T}_{4}$ group had $\mathrm{FT}_{4}, \mathrm{FT}_{3}$ and $\mathrm{FT}_{3} / \mathrm{FT}_{4}$ levels equivalent to those of the controls. The $\mathrm{HT}$-alone group had significantly lower $\mathrm{FT}_{4}(P<0.01)$, equivalent $\mathrm{FT}_{3}(P=0.083)$, and significantly higher $\mathrm{FT}_{3} / \mathrm{FT}_{4}(P<0.001)$ ratios than the controls.
\end{abstract}

Conclusions: The presence of the remnant thyroid tissue was associated with different thyroid hormone balances in thyroidectomized patients, suggesting that $T_{3}$ production by remnant thyroid tissue has a substantial effect on the maintenance of postoperative serum $T_{3}$ levels.

\section{Introduction}

There are two thyroid hormones, thyroxine $\left(\mathrm{T}_{4}\right)$ and triiodothyronine $\left(T_{3}\right)$. $T_{3}$ is the biologically active thyroid hormone. In normal subjects, $100 \%$ of $\mathrm{T}_{4}$ is secreted by the thyroid, about $20 \%$ of $\mathrm{T}_{3}$ is secreted from the thyroid gland, and about $80 \%$ of $\mathrm{T}_{3}$ is derived from the conversion of $\mathrm{T}_{4}$ to $\mathrm{T}_{3}$ in extra-thyroidal peripheral tissues (1). A relative $T_{3}$ deficiency may thus be present in athyreotic patients during $\mathrm{T}_{4}$ monotherapy. Several studies $(2,3,4,5)$ compared postoperative $\mathrm{T}_{3}$ levels in patients on $\mathrm{L}-\mathrm{T}_{4}$ therapy with their own preoperative levels or those in euthyroid controls. We reported that serum $\mathrm{T}_{3}$ levels were inappropriately low in patients who had undergone a total thyroidectomy (TT) and were on $\mathrm{L}_{-} \mathrm{T}_{4}$ supplementation and that a moderately thyroid-stimulating hormone (TSH)-suppressive dose of $\mathrm{L}_{-} \mathrm{T}_{4}$ was required to achieve their preoperative native serum $\mathrm{T}_{3}$ levels (2). Jonklaas et al. (3) reported that there were no significant decreases in $T_{3}$ levels in patients on $\mathrm{L}-\mathrm{T}_{4}$ supplementation compared with their preoperative $T_{3}$ levels within the group as a whole, although a higher ratio of free $\mathrm{T}_{4}\left(\mathrm{FT}_{4}\right)$ to $\mathrm{T}_{3}$ ratio was

Published by Bioscientifica Ltd. 
necessary to achieve this. Gullo et al. (4) studied 1811 athyreotic subjects with normal TSH levels and 3875 euthyroid controls, and they found that serum free $T_{3}$ $\left(\mathrm{FT}_{3}\right)$ levels of the athyreotic subjects were lower than those of the euthyroid controls, whereas the athyreotic subjects' serum $\mathrm{FT}_{4}$ levels were higher. Hoermann et al. (5) recently reported that in 50 carcinoma patients who underwent TT and showed normal TSH levels postoperatively, the $\mathrm{FT}_{3}$ levels were lower than those of controls, whereas the $\mathrm{FT}_{4}$ levels were higher than those of the controls. These findings suggest that the interrelation among serum $\mathrm{T}_{4}, \mathrm{~T}_{3}$ and $\mathrm{TSH}$ levels might differ according to the postoperative presence or absence of thyroid tissue. However, to the best of our knowledge this hypothesis has not been investigated in detail.

Although hemithyroidectomy (HT) is associated with a risk of hypothyroidism, few studies have evaluated the thyroidal function including serum $\mathrm{T}_{3}$ levels of HT patients, because patients who had normal serum TSH and $\mathrm{FT}_{4}$ levels were generally considered to have euthyroidism (6). Some investigators reported that patients who underwent a HT had approximately the same serum $\mathrm{T}_{3}$ levels compared to their preoperative native levels or those in controls $(7,8)$, but another group did not obtain such results (9). Most of the previous studies have some flaws such as the heterogeneity of patients or a small sample size $(n=28-35)$. The cases in Lombardi et al. (7) and Toft Kristensen et al. (9) were only identified as euthyroid goiter; therefore, the cases in these studies may contain follicular tumor, thyroid dyshormonogenesis, or giant Hashimoto thyroiditis. These diseases reveal normal thyroid hormone levels but high $\mathrm{T}_{3} / \mathrm{T}_{4}$ ratio. In the present study, our cases were identified as papillary thyroid carcinoma that did not affect the thyroidal conversion of $T_{4}$ to $T_{3}$ (10). Moreover, in these reports, the postoperative serum TSH levels were increased compared to preoperative native levels or those of controls $(7,8,9)$. It is possible that TSH stimulates both type 1 (D1) and type 2 (D2) deiodinases, which convert $T_{4}$ to $T_{3}$ mediated by a cAMP signaling pathway $(11,12,13)$.

In the present study, we first measured serum $\mathrm{TSH}$, $\mathrm{FT}_{4}$, and $\mathrm{FT}_{3}$ levels and the $\mathrm{FT}_{3} / \mathrm{FT}_{4}$ ratios on three groups of euthyroid patients who underwent a thyroidectomy for papillary thyroid carcinoma: the patients who underwent a TT and received supplemental $\mathrm{L}-\mathrm{T}_{4}$, the patients who underwent $\mathrm{HT}$ and received supplemental $\mathrm{L}-\mathrm{T}_{4}$, and the patients who underwent a HT alone, both before and after stabilization of the thyroid profiles 12 months after the thyroidectomy. We also compared gender, age, BMI, and serum thyroid parameters among the groups.
Postoperative TSH levels differed from the preoperative levels in two patient groups. Moreover, gender, age, and TSH levels differed among groups. Therefore, we further compared serum $\mathrm{FT}_{4}$ and $\mathrm{FT}_{3}$ levels and the $\mathrm{FT}_{3} / \mathrm{FT}_{4}$ ratio measured postoperatively in each patient group with those in a healthy control group matched by gender, age, and serum TSH level.

\section{Subjects and methods}

\section{Patients}

From their medical records, we identified 1012 consecutive patients who underwent a thyroidectomy for papillary thyroid carcinoma between October 2011 and February 2013 at Kuma Hospital and were followed at least for 18 months postoperatively. The inclusion criteria for the present study were as follows: the patient underwent a TT or HT; the patient had been diagnosed with papillary thyroid carcinoma; the patient had a preoperative TSH level within the laboratory reference range (0.3-5.0 $\mu \mathrm{U} / \mathrm{ml})$; and the patient had a final postoperative TSH level within the laboratory reference range.

The exclusion criteria were as follows: patients who underwent near-total or subtotal thyroidectomy; patients with thyroid malignancies other than papillary carcinoma; patients with Graves' disease, Hashimoto thyroiditis, thyroid dysfunction, thyroid dyshormonogenesis, or autonomously functioning thyroid nodules; patients with chronic or serious diseases such as cardiac, pulmonary, hepatic, and renal diseases; patients who were taking drugs known to affect thyroid function or thyroid hormone metabolism, such as a steroid, estrogen, amiodarone, lithium, $\beta$-blocker, sucralfate, iron, or iodine-containing drugs; patients who were pregnant or lactating; patients who were under 'suppressive' $\mathrm{L}_{-} \mathrm{T}_{4}$ treatment for high-risk thyroid cancer; and patients who did not achieve normal serum TSH levels. Finally, 253 consecutive patients were enrolled in the present study.

The patients who underwent a TT were initially administered $2.0 \mu \mathrm{g} / \mathrm{kg}$ of $\mathrm{L}_{-} \mathrm{T}_{4}$ daily after surgery. Thyroid function tests were performed 1 month after surgery and every 3-6 months thereafter. If necessary, $\mathrm{L}^{-\mathrm{T}_{4}}$ was administered and doses were adjusted with the intention to maintain the patient's target serum TSH values. On the other hand, the patients who underwent a HT were initially followed up without $\mathrm{L}_{-} \mathrm{T}_{4}$ after surgery. Thyroid function tests were performed 1 month after surgery and every 3-6 months thereafter. If a patient developed hypothyroidism, L- $\mathrm{T}_{4}$ was administered and doses were 
adjusted to maintain the patient's serum TSH values within the reference range. The ultimate mean daily doses of $\mathrm{L}_{-} \mathrm{T}_{4}$ administered were $2.02 \mu \mathrm{g} / \mathrm{kg}$ per day for the patients who underwent a TT and received supplemental L-T $\mathrm{T}_{4}$ and $1.07 \mu \mathrm{g} / \mathrm{kg}$ per day for the patients who underwent a HT and received supplemental $\mathrm{L}_{\mathrm{T}} \mathrm{T}_{4}$.

Of the 253 patients, 103 patients underwent a TT and 150 patients underwent a HT. Among the latter, 56 patients (37\%) developed hypothyroidism postoperatively and received supplemental $\mathrm{L}-\mathrm{T}_{4}$ treatment. Thus, the present patients were divided into three groups: 103 patients with $\mathrm{TT}+$ supplemental $\mathrm{L}-\mathrm{T}_{4}$ therapy, 56 patients with $\mathrm{HT}+$ supplemental $\mathrm{L}-\mathrm{T}_{4}$ therapy, and 94 patients with HT alone (Fig. 1).

\section{Matched control subjects}

A continuous series of 951 euthyroid subjects who were examined at Kuma Hospital during the same period and who did not have clinical or laboratory signs of thyroid diseases served as controls. Subjects with positive antithyroid peroxidase (TPO) or anti-thyroglobulin (Tg) antibody test results or with abnormal findings on an ultrasound examination were excluded. The other exclusion criteria were the same as those used for the selection of the present patients described above. To balance the covariates including age, sex, and serum TSH levels between the patients and controls, we used Mahalanobis-metric matching for choosing the control subjects for each patient group, as described by Rubin (14). Control

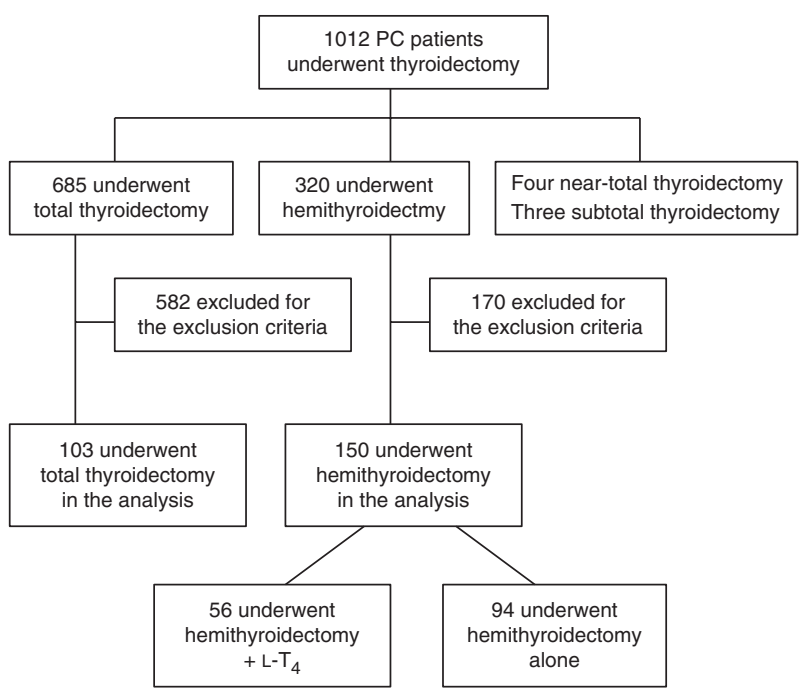

Figure 1

Flow chart of study. PC, papillary carcinoma. subjects for each group of patients were chosen from among the 951 subjects selected above by 1:1 matching.

The present study was approved by the Ethical Committee at Kuma Hospital, and all patients gave informed consent.

\section{Thyroid function tests}

Each patient's presurgical thyroid profile was obtained 2 days before the surgery. The postoperative thyroid profiles were obtained after stabilization of the thyroid profiles, usually 12 months after the thyroidectomy. For the patients who were taking $\mathrm{L}-\mathrm{T}_{4}$, blood samples were obtained in the morning and after the ingestion of $\mathrm{L}-\mathrm{T}_{4}$.

The patients' and controls' serum levels of $\mathrm{TSH}, \mathrm{FT}_{4}$, and $\mathrm{FT}_{3}$ were measured with a chemiluminescent immunoassay (ARCHTECT i2000, Abbott Japan). The intra-assay coefficients of variation and the inter-assay coefficients of variation were $1.1-5.0$ and $1.7-5.3 \%$ for the TSH assay, 2.3-5.3 and 3.6-7.8\% for the $\mathrm{FT}_{4}$ assay, and 1.4-4.2 and $2.3-5.0 \%$ for the $\mathrm{FT}_{3}$ assay. The reference ranges in our hospital are $0.3-5.0 \mathrm{mU} / 1$ for TSH, 9.0-20.6 pmol/l for $\mathrm{FT}_{4}$, 2.61-5.68 pmol/l for $\mathrm{FT}_{3}$, and $0.21-0.39$ for the $\mathrm{FT}_{3} / \mathrm{FT}_{4}$ ratio.

\section{Statistical analysis}

Treatment effects (pre-thyroidectomy or controls vs postthyroidectomy) were analyzed by a paired $t$-test in case of normal distribution and by the Wilcoxon test in case of nonparametric distribution. The postoperative group comparisons were analyzed by an unpaired $t$-test in case of normal distribution and by the Mann-Whitney $U$ test in case of nonparametric distribution, using Bonferroni corrections for multiple comparisons. Significance was accepted at $P<0.05$. Mahalanobis-metric matching was performed using R package (version 3.0.2. R Core Team, Vienna, Austria). Other statistical analyses were performed using StatFlex (version 6.0. Artech Co., Ltd, Osaka, Japan).

\section{Results}

\section{Postoperative vs preoperative thyroid function profiles in the three patient groups}

Table 1 shows the TSH, $\mathrm{FT}_{4}$, and $\mathrm{FT}_{3}$ levels and the $\mathrm{FT}_{3} / \mathrm{FT}_{4}$ ratios before and after thyroidectomy in each patient group. In the $\mathrm{TT}+\mathrm{L}-\mathrm{T}_{4}$ group, compared to their preoperative values, the patients' postoperative serum TSH values were significantly decreased $(P<0.001)$, their postoperative $\mathrm{FT}_{4}$ levels were significantly increased 
Table 1 Pre- and post-thyroidectomy serum levels of $\mathrm{TSH}, \mathrm{FT}_{4}, \mathrm{FT}_{3}$, and $\mathrm{FT}_{3} / \mathrm{FT}_{4}$ in the three patient groups. Statistical significance (pre- vs post-thyroidectomy) was analyzed by paired $t$-test or by Wilcoxon signed-rank test. Values indicate median (25th to 75th percentiles)

\begin{tabular}{l}
\hline Patients groups \\
\hline Total thyroidectomy $+\mathrm{L}-\mathrm{T}_{4}(n=103)$ \\
Pre-thyroidectomy \\
Post-thyroidectomy \\
$P$ value \\
Hemithyroidectomy $+\mathrm{L}-\mathrm{T}_{4}(n=56)$ \\
Pre-thyroidectomy \\
Post-thyroidectomy \\
$P$ value \\
Hemithyroidectomy alone $(n=94)$ \\
Pre-thyroidectomy \\
Post-thyroidectomy \\
$P$ value
\end{tabular}

\begin{tabular}{c}
\hline TSH $(\mathrm{mU} / \mathrm{l})$ \\
\hline $1.52(1.02-2.13)$ \\
$0.78(0.49-1.50)$ \\
$<0.001$ \\
$1.84(1.30-2.63)$ \\
$1.86(1.16-2.75)$ \\
0.136 \\
$1.07(0.73-1.51)$ \\
$2.41(1.67-3.37)$ \\
$<0.001$ \\
\hline
\end{tabular}

\begin{tabular}{c}
\hline $\mathbf{F T}_{\mathbf{4}}(\mathrm{pmol} / \mathrm{l})$ \\
\hline $14.4(13.3-15.4)$ \\
$17.2(15.7-18.9)$ \\
$<0.001$ \\
$13.8(12.6-14.7)$ \\
$14.3(13.2-15.4)$ \\
0.024 \\
$14.4(13.1-15.3)$ \\
$12.9(12.1-13.6)$ \\
$<0.001$
\end{tabular}

\begin{tabular}{c}
\hline $\mathbf{F T}_{\mathbf{3}}(\mathrm{pmol} / \mathrm{l})$ \\
\hline $4.45(4.06-4.81)$ \\
$4.29(3.96-4.65)$ \\
0.023 \\
\\
$4.38(4.06-4.65)$ \\
$4.35(3.98-4.61)$ \\
0.498 \\
$4.31(3.89-4.77)$ \\
$4.43(4.04-4.65)$ \\
0.204
\end{tabular}

\begin{tabular}{c}
\hline $\mathbf{F T}_{\mathbf{3}} / \mathbf{F T}_{\mathbf{4}}$ \\
\\
$0.31(0.28-0.34)$ \\
$0.25(0.22-0.28)$ \\
$<0.001$ \\
\\
$0.32(0.29-0.34)$ \\
$0.29(0.27-0.33)$ \\
0.017 \\
$0.30(0.27-0.33)$ \\
$0.34(0.32-0.37)$ \\
$<0.001^{\mathrm{a}}$ \\
\hline
\end{tabular}

$\mathrm{TSH}$, thyroid-stimulating hormone; $\mathrm{FT}_{4}$, free thyroxine; $\mathrm{FT}_{3}$, free triiodothyronine. aWilcoxon signed-rank test.

$(P<0.001)$, and their postoperative $\mathrm{FT}_{3}$ levels were significantly decreased $(P=0.023)$, although all of these values were within their reference ranges (Table 1 ).

In the $\mathrm{HT}+\mathrm{L}-\mathrm{T}_{4}$ group, the postoperative $\mathrm{FT}_{3}$ levels and TSH levels did not show significant differences from their preoperative values, and the postoperative $\mathrm{FT}_{4}$ levels were slightly and significantly increased $(P=0.024)$, although all of these values were within their reference ranges (Table 1).

In the HT-alone group, the patients' postoperative $\mathrm{FT}_{3}$ levels did not differ significantly from their preoperative values, whereas their postoperative serum TSH values were significantly increased $(P<0.001)$ and the postoperative $\mathrm{FT}_{4}$ levels were significantly decreased $(P<0.001)$, although all of the values were within their reference ranges. Thus, the three groups of patients showed different thyroid function profiles, although the values were all within their reference ranges (Table 1).

Regarding the $\mathrm{FT}_{3} / \mathrm{FT}_{4}$ ratio, the three groups showed different changes postoperatively: the TT + supplemental $\mathrm{L}-\mathrm{T}_{4}$ patients showed significant decreases in the ratio $(P<0.001)$; the HT $+\mathrm{L}-\mathrm{T}_{4}$ patients had slight but significant decreases in the ratio $(P=0.017)$, and the HT-alone patients showed increases in the ratio $(P<0.001)$ (Table 1$)$.

\section{Clinical characteristics among the three patient groups}

Characteristics among the three patient groups are given in Table 2. Gender ratios of the $\mathrm{HT}+\mathrm{L}-\mathrm{T}_{4}$ group were significantly different from those of the other two groups $(P<0.001)$. Ages of the HT $+\mathrm{L}-\mathrm{T}_{4}$ group were significantly higher than those of the HT alone group $(P<0.05)$. BMI

Table 2 Clinical characteristics among the three patients groups. Statistical significance was analyzed by the $\chi^{2}$ test (gender), unpaired $t$-test, or Mann-Whitney $U$ test using Bonferroni corrections for multiple comparisons. Values indicate median and interquartile ranges.

\begin{tabular}{|c|c|c|c|c|c|c|}
\hline \multirow[b]{2}{*}{ Parameters } & \multirow[b]{2}{*}{$\mathbf{T T}+\mathbf{L}-\mathbf{T}_{\mathbf{4}}$} & \multirow[b]{2}{*}{$\mathbf{H T}+\mathbf{L}-\mathbf{T}_{\mathbf{4}}$} & \multirow[b]{2}{*}{ HT alone } & \multicolumn{3}{|c|}{$P$ value } \\
\hline & & & & $\mathrm{TT}+\mathrm{L}-\mathrm{T}_{4}$ vs HT$+\mathrm{L}-\mathrm{T}_{4}$ & $\mathrm{TT}+\mathrm{L}-\mathrm{T}_{4}$ vs $\mathrm{HT}$ alone & $\mathrm{HT}+\mathrm{L}-\mathrm{T}_{4}$ vs $\mathrm{HT}$ alone \\
\hline$n$ & 103 & 56 & 94 & & & \\
\hline Gender (M/F) & $27 / 76$ & $8 / 48$ & $26 / 68$ & $<0.001$ & 0.96 & $<0.001$ \\
\hline Age (years) & $51(40-63)$ & $58(43-65)$ & $50(41-60)$ & 0.24 & 1.00 & $<0.05$ \\
\hline BMI $\left(\mathrm{kg} / \mathrm{m}^{2}\right)$ & $23.0(3.7)$ & $23.1(3.6)$ & $23.6(3.7)$ & 0.84 & 1.00 & 1.00 \\
\hline TSH (mU/I) & $0.78(1.01)$ & $1.86(1.59)$ & $2.41(1.70)$ & $<0.001$ & $<0.001$ & $0.07^{a}$ \\
\hline $\mathrm{FT}_{4}(\mathrm{pmol} / \mathrm{l})$ & $17.2(3.2)$ & $14.3(2.2)$ & $12.9(1.5)$ & $<0.001$ & $<0.001$ & $<0.001$ \\
\hline $\mathrm{FT}_{3}(\mathrm{pmol} / \mathrm{l})$ & $4.29(0.68)$ & $4.35(0.63)$ & $4.43(0.61)$ & 1.00 & 0.44 & 0.52 \\
\hline $\mathrm{FT}_{3} / \mathrm{FT}_{4}$ & $0.25(0.05)$ & $0.29(0.06)$ & $0.34(0.05)$ & $<0.001$ & $<0.001^{a}$ & $<0.001$ \\
\hline
\end{tabular}

$\mathrm{TSH}$, thyroid-stimulating hormone; $\mathrm{FT}_{4}$, free thyroxine; $\mathrm{FT}_{3}$, free triiodothyronine; $\mathrm{TT}$, total thyroidectomy; HT, hemithyroidectomy. ${ }^{a}$ Mann-Whitney $U$ test. 
values of the three groups were similar among groups. Serum TSH levels in the TT $+\mathrm{L}-\mathrm{T}_{4}$ group were significantly lower than those of the other two groups $(P<0.001)$. Serum $\mathrm{FT}_{4}$ and $\mathrm{FT}_{3} / \mathrm{FT}_{4}$ levels of one of the three groups were different from those of the other two groups. Serum $\mathrm{FT}_{3}$ levels of the three groups were not significantly different among groups.

\section{Postoperative thyroid function profiles of the patients compared to those of the control subjects matched with the Mahalanobis-metric method}

In the $\mathrm{TT}+\mathrm{L}-\mathrm{T}_{4}$ group, the postoperative serum $\mathrm{FT}_{4}$ levels were significantly higher than those of the matched controls (17.2 (15.7-18.9) vs 14.3 (13.3-15.2) pmol/l respectively, $P<0.001$ (median (25th to 75 th percentiles)) and the postoperative serum $\mathrm{FT}_{3}$ levels were significantly lower (4.29 (3.96-4.65) vs $4.42(4.12-4.74) \mathrm{pmol} / \mathrm{l}$ respectively, $P=0.008)$. The serum $\mathrm{FT}_{3} / \mathrm{FT}_{4}$ ratios were significantly lower than those of the matched controls $(0.25(0.22-0.28)$ vs 0.31 (0.28-0.34) respectively, $P<0.001)$ (Fig. 2A).

In the $\mathrm{HT}+\mathrm{L}-\mathrm{T}_{4}$ group, the postoperative serum $\mathrm{FT}_{4}$ and $\mathrm{FT}_{3}$ levels and $\mathrm{FT}_{3} / \mathrm{FT}_{4}$ ratios did not differ significantly from those of the matched controls (14.3 (13.2-15.4) vs 13.8 (12.7-14.9) $\mathrm{pmol} / \mathrm{l}, P=0.094 ; 4.35$ (3.98-4.61) vs 4.19 (3.77-4.47) $\mathrm{pmol} / \mathrm{l}, P=0.082$; and $0.29(0.27-0.33)$ vs 0.32 (0.29-0.34) respectively, $P=0.978$ ) (Fig. 2B).

In the HT-alone group, the postoperative serum $\mathrm{FT}_{4}$ levels were significantly lower than those of the controls (12.9 (12.1-13.6) vs 13.6 (12.3-14.5) pmol/l, $P=0.007)$, but the postoperative serum $\mathrm{FT}_{3}$ levels did not differ significantly from those of the matched controls (4.43 (4.04-4.65) vs 4.25 (3.92-4.56) pmol/l, $P=0.083)$, and the serum $\mathrm{FT}_{3} / \mathrm{FT}_{4}$ ratios were significantly higher than those of the controls $(0.34(0.32-0.37)$ vs $0.32(0.29-0.35)$, $P<0.001$ ) (Fig. 2C).

\section{Discussion}

The results of the present study demonstrate that in patients who underwent TT and showed normal TSH levels postoperatively, the postoperative serum $\mathrm{FT}_{3}$ levels were lower than their preoperative native levels and those of the matched euthyroid controls despite the increased $\mathrm{FT}_{4}$ levels. The results obtained for the patients with TT + supplemental $\mathrm{L}-\mathrm{T}_{4}$ in the present study were consistent with those of our previous report (2) and the reports by Gullo et al. (4) and Hoermann et al. (5). These findings suggest that the reason underlying the decreased serum $\mathrm{T}_{3}$ levels in such patients is the lack of intra-thyroidal
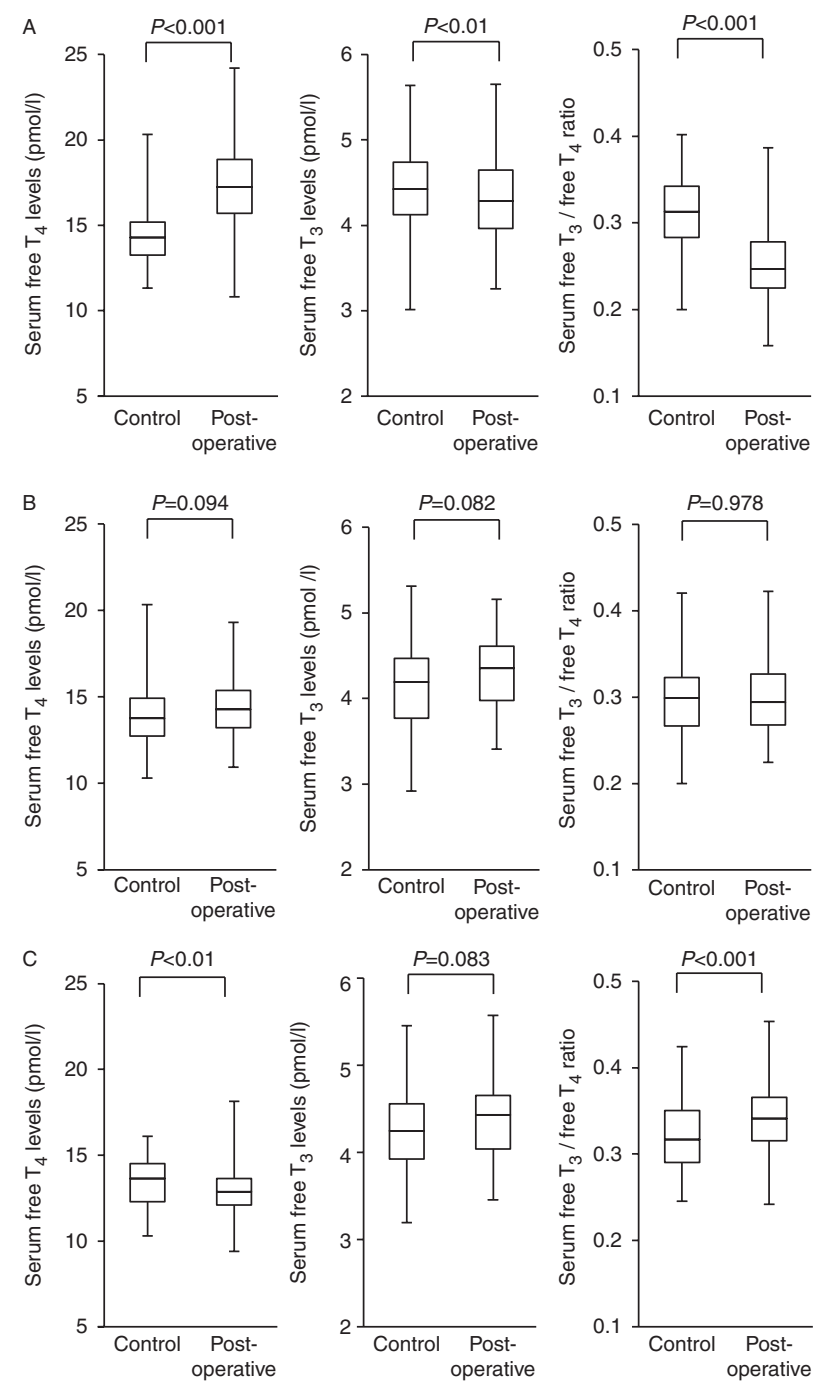

\section{Figure 2}

Postoperative serum $\mathrm{FT}_{4}, \mathrm{FT}_{3}$, and $\mathrm{FT}_{3} / \mathrm{FT}_{4}$ levels of patients who underwent thyroidectomy and those of the euthyroid controls matched by age, sex, and serum TSH levels. (A) The total thyroidectomy $+\mathrm{L}-\mathrm{T}_{4}$ group $(n=103)$. (B) The hemithyroidectomy $+\mathrm{L}-\mathrm{T}_{4}$ group $(n=56)$. (C) The hemithyroidectomy-alone group $(n=94)$. $\mathrm{FT}_{4}$, free thyroxine; $\mathrm{FT}_{3}$, free triiodothyronine. The top, bottom, and middle lines of the boxes correspond to the 75th, 25th, and 50th percentiles (median), respectively. The whiskers extend from the minimum to the maximum.

$\mathrm{T}_{3}$ production caused by the absence of the thyroid gland. These data suggest that TSH-suppressive doses of $\mathrm{L}^{-\mathrm{T}_{4}}$ are required to achieve normal $\mathrm{T}_{3}$ levels in patients who have undergone TT not only for thyroid cancer but also for other diseases such as Graves' disease, multinodular disease, and Hashimoto thyroiditis. 
Here we studied a large number of patients with papillary thyroid cancer and observed that the postoperative serum $\mathrm{FT}_{3}$ levels of the patients who underwent a HT alone were substantially equivalent to those of the controls matched by serum TSH level, although the patients' serum $\mathrm{FT}_{4}$ levels were significantly lower, resulting in a higher $\mathrm{FT}_{3} / \mathrm{FT}_{4}$ ratio. The mechanism of this increased $\mathrm{FT}_{3} / \mathrm{FT}_{4}$ ratio in patients who have undergone a HT alone remains unknown. Lum et al. (15) reported that a non-thyroidal, non-TSH-mediated system exists for maintaining circulating $\mathrm{T}_{3}$ levels in a state of $\mathrm{T}_{4}$ deficiency.

Considered in conjunction with the decreased $\mathrm{FT}_{3} / \mathrm{FT}_{4}$ ratio in the present athyreotic patients who underwent a TT, this increased $\mathrm{FT}_{3} / \mathrm{FT}_{4}$ ratio in the patients who underwent HT seems to be caused by an increasing production of $\mathrm{T}_{3}$ in the remnant thyroid tissue. Maia et al. (16) reported that D2 is expressed in the human thyroid gland and is postulated to play an important role as a source of plasma $T_{3}$. As a matter of fact, it has been suggested that the increased D2 in the thyroid gland may account for the status of a low $\mathrm{FT}_{4}$ with relatively high or normal circulating $\mathrm{T}_{3}$ levels in other thyroid diseases, such as follicular carcinoma (10), thyroglobulin gene abnormalities (17), and $\mathrm{T}_{3}$-predominant Graves' disease (18). Very recently, Hoermann et al. reported the association between thyroid volume and deiodinase activity. They investigated deiodinase activity in $\mathrm{L}^{-} \mathrm{T}_{4}$-treated patients from thyroid volume groups (cut-off $5 \mathrm{ml}$ ) and indicated that patients with a post-interventional lower residual volume $(<5 \mathrm{ml})$ have significantly reduced deiodinase activity and lowered $\mathrm{T}_{3}$ levels compared to patients with a higher residual thyroid volume (19). This result suggests that residual thyroid capacity plays a significant role in the physiological process of $T_{3}$ homeostasis in humans and is in good agreement with this study. A further proper study including the determination of D2 activity in the remnant thyroid tissue may be necessary to clarify the mechanism of the higher $\mathrm{FT}_{3} / \mathrm{FT}_{4}$ ratio in these patients.

In our patients who underwent a $\mathrm{HT}$ and were treated with $\mathrm{L}-\mathrm{T}_{4}$ therapy, the postoperative serum $\mathrm{FT}_{4}$ and $\mathrm{FT}_{3}$ levels and $\mathrm{FT}_{3} / \mathrm{FT}_{4}$ ratio were substantially equivalent to those of the matched controls. The present findings thus demonstrate that the serum thyroid hormone balances in these patients are similar to the preoperative levels in the physiological normal condition and to those of euthyroid controls. Because the dose of $\mathrm{L}-\mathrm{T}_{4}$ was less in the patients who underwent a HT than in the patients who underwent a TT, we speculate that the reason the decrease of $T_{3}$ levels was not observed in these patients was the production of $\mathrm{T}_{3}$ in the remnant thyroid tissue.
Considerable controversy exists regarding the management of the thyroid function status in patients who have undergone a thyroidectomy and are receiving postoperative $\mathrm{L}-\mathrm{T}_{4}$ therapy. Since the negative feedback relationship between serum $\mathrm{T}_{4}$ levels and serum TSH levels is a consistent inverse relationship, most endocrinologists consider the serum TSH level a very sensitive indicator of thyroid function. However, serum TSH levels only reflect the feedback effect of thyroid hormones at the hypothalamic-pituitary level. The TSH secretion from the pituitary is negatively regulated primarily by $\mathrm{T}_{3}$ produced locally via the conversion of $\mathrm{T}_{4}$ transported from the peripheral blood, which is in keeping with the view that serum $\mathrm{T}_{4}$ rather than $\mathrm{T}_{3}$ has a dominant role in regulating TSH secretion (20). On the other hand, $\mathrm{T}_{3}$ transported from the peripheral blood also has a role in regulating TSH secretion by the pituitary. This has been well documented in patients acutely given large amounts of propylthyouracyl, which inhibits the peripheral synthesis of $\mathrm{T}_{3}(21)$.

$\mathrm{L}-\mathrm{T}_{4}$ alone administered to rats that had undergone a TT at doses to normalize the plasma TSH levels did not normalize the $\mathrm{T}_{3}$ contents in some tissues (22). Alevizaki et al. (23) reported that athyreotic patients with $\mathrm{T}_{4}$-treated hypothyroidism and normal TSH levels had lower $\mathrm{T}_{3}$ and lower sex hormone-binding globulin (SHBG) levels than controls. These data suggest that normal TSH levels cannot guarantee euthyroidism in peripheral tissues in postthyroidectomized athyreotic patients under $\mathrm{L}-\mathrm{T}_{4}$ therapy. Most clinicians generally believe that a low serum TSH level indicates subclinical thyrotoxicosis and is a risk factor for cardiac dysfunction or osteoporosis (24). However, such a clinical outcome in subclinical thyrotoxicosis seems to be unclear in patients with moderately low TSH levels (25). Thus, in patients who have undergone a TT, TSH-suppressive treatment by $\mathrm{L}_{-} \mathrm{T}_{4}$ for high-risk thyroid cancer may not necessarily cause thyrotoxicosis.

The present study has some possible limitations. First, it has been reported that serum $\mathrm{FT}_{4}$ and $\mathrm{FT}_{3}$ levels increased transiently after the ingestion of $\mathrm{L}-\mathrm{T}_{4}(26,27)$. In consideration of such an increment, the evaluation of diurnal variation or the area under the curve (AUC) by repeated blood sampling may be the best method; however, it is practically difficult to carry out such an examination in many patients. In the present study, we evaluated the blood sampling data after the ingestion of $\mathrm{L}_{-} \mathrm{T}_{4}$. The result (i.e., the $\mathrm{FT}_{3}$ levels were lower than the preoperative $\mathrm{FT}_{3}$ levels) suggests that the postoperative $\mathrm{FT}_{3}$ levels in the serum remained relatively low for most of the day. In contrast, the serum $\mathrm{FT}_{4}$ levels were higher than the preoperative levels, and this could be affected by the blood sampling after the 
consumption of $\mathrm{L}^{-} \mathrm{T}_{4}$. Second, in this retrospective study, we did not measure the thyroid volumes. In general, it is believed that about $20 \%$ of the $\mathrm{T}_{3}$ pool is secreted from the thyroid gland, while we found that a marked contribution that is attributed to the remnant would be at variance with this reported proportion in humans. It would be possible to put a rough quantitative estimate on thyroidal $\mathrm{T}_{3}$ contributions by comparing pre- and postoperative levels and changes in volume. Properly designed studies including measures of the thyroid volumes are needed to clarify the quantitative estimate on thyroidal $\mathrm{T}_{3}$ contributions in the postoperative patients. In addition, the present study is restricted to the patients with normal serum TSH levels. It might be interesting to get some additional comparisons with another large entity, thyroidectomized patients with advanced thyroid cancer maintained on a TSH-suppressive regimen.

In conclusion, the results of the present study showed that in thyroidectomized patients, the presence of thyroid tissue causes significant differences in the interrelation of $\mathrm{FT}_{4}, \mathrm{FT}_{3}$, and TSH levels. Our findings suggest that $\mathrm{T}_{3}$ production by the remnant thyroid tissue has a substantial effect on the maintenance of serum $\mathrm{T}_{3}$ levels in thyroidectomized patients. The question arises as to whether any of the patients in the three groups were in a euthyroid condition: those with normal $\mathrm{TSH}$, mildly high $\mathrm{FT}_{4}$, and mildly low $\mathrm{FT}_{3}$ levels among the $\mathrm{TT}+\mathrm{L}-\mathrm{T}_{4}$ patients, those with mildly suppressed $\mathrm{TSH}$, mildly high $\mathrm{FT}_{4}$, and mildly low $\mathrm{FT}_{3}$ in the TT+supplemental $\mathrm{L}-\mathrm{T}_{4}$ group, or those with normal $\mathrm{TSH}$, mildly low $\mathrm{FT}_{4}$, and normal $\mathrm{FT}_{3}$ among the HT-alone patients. These patients live in a chronic condition of abnormal thyroid hormone status for the remainder of their lives. Therefore, even if the thyroidal dysfunction may be subtle, its long-term effects cannot be overlooked.

In 2014, the American Thyroid Association stated in a guideline that patients with hypothyroidism treated with L- $\mathrm{T}_{4}$ to achieve normal serum TSH values may have serum $\mathrm{T}_{3}$ levels that are at the lower end of the reference range, or even below the reference range (28). The guideline also mentioned that there is insufficient beneficial evidence to recommend that treatment with $\mathrm{L}-\mathrm{T}_{4}$ be targeted to achieve low-normal TSH values or high-normal $\mathrm{T}_{3}$ values in patients with hypothyroidism who are athyreotic (28). The major weakness of this study, and most of the studies like this, concerns its retrospective analysis that may eliminate the ability to obtain strong conclusions. Prospective studies including measures of the patients' well-being and/or metabolic markers such as lipid or bone markers are needed to clarify the best method of managing postoperative thyroid function in patients.
Declaration of interest

The authors declare that there is no conflict of interest that could be perceived as prejudicing the impartiality of the research reported.

\section{Funding}

This research did not receive any specific grant from any funding agency in the public, commercial or not-for-profit sector.

\section{Author contribution statement}

$\mathrm{M}$ Ito and A Miyauchi constructed the study design. M Ito analyzed the data and wrote the manuscript. The other coauthors contributed by performing surgery and/or caring for the patients. All authors read and approved the final manuscript.

\section{References}

1 Pilo A, Iervasi G, Vitek F, Ferdeghini M, Cazzuola F \& Bianchi R. Thyroidal and peripheral production of 3,5,3'-triiodothyronine in humans by multicompartmental analysis. American Journal of Physiology $1990258715-726$.

2 Ito M, Miyauchi A, Morita S, Kudo T, Nishihara E, Kihara M, Takamura Y, Ito Y, Kobayashi K, Miya A et al. TSH-suppressive doses of levothyroxine are required to achieve preoperative native serum triiodothyronine levels in patients who have undergone total thyroidectomy. European Journal of Endocrinology/European Federation of Endocrine Societies 2012167 373-378. (doi:10.1530/EJE-11-1029)

3 Jonklaas J, Davidson B, Bhagat S \& Soldin SJ. Triiodothyronine levels in athyreotic individuals during levothyroxine therapy. Journal of the American Medical Association 2008299 769-777. (doi:10.1001/jama. 299.7.769)

4 Gullo D, Latina A, Frasca F, Le Moli R, Pellegriti G \& Vigneri R. Levothyroxine monotherapy cannot guarantee euthyroidism in all athyreotic patients. PLOS ONE 20116 e22552. (doi:10.1371/journal. pone.0022552)

5 Hoermann R, Midgley JE, Giacobino A, Eckl WA, Wahl HG, Dietrich JW \& Larisch R. Homeostatic equilibria between free thyroid hormones and pituitary thyrotropin are modulated by various influences including age, body mass index and treatment. Clinical Endocrinology $2014 \mathbf{8 1}$ 907-915. (doi:10.1111/cen.12527)

6 Verloop H, Louwerens M, Schoones JW, Kievit J, Smit JW \& Dekkers OM. Risk of hypothyroidism following hemithyroidectomy: systematic review and meta-analysis of prognostic studies. Journal of Clinical Endocrinology and Metabolism 201297 2243-2255. (doi:10.1210/jc.2012-1063)

7 Lombardi G, Panza N, Lupoli G, Leonello D, Carlino M \& Minozzi M. Study of the pituitary-thyroid axis in euthyroid goiter after partial thyroidectomy. Journal of Endocrinological Investigation 19836 485-487. (doi:10.1007/BF03348349)

8 Lindblom $\mathrm{P}$, Valdemarsson S, Lindergård $\mathrm{B}$, Westerdahl J \& Bergenfelz A. Decreased levels of ionized calcium one year after hemithyroidectomy: importance of reduced thyroid hormones. Hormone Research 200155 81-87. (doi:10.1159/000049975)

9 Toft Kristensen T, Larsen J, Pedersen PL, Feldthusen AD, Ellervik C, Jelstrup S \& Kvetny J. Persistent cellular metabolic changes after hemithyroidectomy for benign euthyroid goiter. European Thyroid Journal 20143 10-16. (doi:10.1159/000357943)

10 Miyauchi A, Takamura Y, Ito Y, Miya A, Kobayashi K, Matsuzuka F, Amino N, Toyoda N, Nomura E \& Nishikawa M. 3,5,3'-Triiodothyronine thyrotoxicosis due to increased conversion of administered levothyroxine in patients with massive metastatic follicular thyroid 
carcinoma. Journal of Clinical Endocrinology and Metabolism 200893 2239-2242. (doi:10.1210/jc.2007-2282)

11 Toyoda N, Nishikawa M, Mori Y, Gondou A, Ogawa Y, Yonemoto T, Yoshimura M, Masaki H \& Inada M. Thyrotropin and triiodothyronine regulate iodothyronine $5^{\prime}$-deiodinase messenger ribonucleic acid levels in FRTL-5 rat thyroid cells. Endocrinology 1992131 389-394. (doi:10.1210/endo.131.1.1319323)

12 Murakami M, Kamiya Y, Morimura T, Araki O, Imamura M, Ogiwara T, Mizuma $\mathrm{H} \&$ Mori M. Thyrotropin receptors in brown adipose tissue: thyrotropin stimulates type II iodothyronine deiodinase and uncoupling protein-1 in brown adipocytes. Endocrinology 2001142 1195-1201. (doi:10.1210/endo.142.3.8012)

13 Bianco AC, Salvatore D, Gereben B, Berry MJ \& Larsen PR. Biochemistry, cellular and molecular biology, and physiological roles of the iodothyronine selenodeiodinases. Endocrine Reviews 200223 38-89. (doi:10.1210/edrv.23.1.0455)

14 Rubin DB. Using multivariate sampling and regression adjustment to control bias in observational studies. Journal of the American Statistical Association 197974 318-328.

15 Lum SM, Nicoloff JT, Spencer CA \& Kaptein EM. Peripheral tissue mechanism for maintenance of serum triiodothyronine values in a thyroxine-deficient state in man. Journal of Clinical Investigation 1984 73 570-575. (doi:10.1172/JCI111245)

16 Maia AL, Kim BW, Huang SA, Harney JW \& Larsen PR. Type 2 iodothyronine deiodinase is the major source of plasma $T_{3}$ in euthyroid humans. Journal of Clinical Investigation 2005115 2524-2533. (doi:10.1172/JCI25083)

17 Kanou Y, Hishinuma A, Tsunekawa K, Seki K, Mizuno Y, Fujisawa H, Imai T, Miura Y, Nagasaka T, Yamada C et al. Thyroglobulin gene mutations producing defective intracellular transport of thyroglobulin are associated with increased thyroidal type 2 iodothyronine deiodinase activity. Journal of Clinical Endocrinology and Metabolism 200792 1451-1457. (doi:10.1210/jc.2006-1242)

18 Ito M, Toyoda N, Nomura E, Takamura Y, Amino N, Iwasaka T, Takamatsu J, Miyauchi A \& Nishikawa M. Type 1 and type 2 iodothyronine deiodinases in the thyroid gland of patients with 3,5,3'-triiodothyronine-predominant Graves' disease. European Journal of Endocrinology/European Federation of Endocrine Societies 2011 164 95-100. (doi:10.1530/EJE-10-0736)

19 Hoermann R, Midgley JE, Larisch R \& Dietrich JW. Integration of peripheral and glandular regulation of triiodothyronine production by thyrotropin in untreated and thyroxine-treated subjects. Hormone and
Metabolic Research = Hormon- und Stoffwechselforschung = Hormones et Métabolisme 2015. In press (doi:10.1055/s-0034-1398616)

20 Silva JE \& Larsen PR. Contributions of plasma triiodothyronine and local thyroxine monodeiodination to triiodothyronine to nuclear triiodothyronine receptor saturation in pituitary, liver, and kidney of hypothyroid rats. Further evidence relating saturation of pituitary nuclear triiodothyronine receptors and the acute inhibition of thyroidstimulating hormone release. Journal of Clinical Investigation $1978 \mathbf{6 1}$ 1247-1259. (doi:10.1172/JCI109041)

21 Geffner DL, Azukizawa M \& Hershman JM. Propylthiouracil blocks extrathyroidal conversion of thyroxine to triiodothyronine and augments thyrotropin secretion in man. Journal of Clinical Investigation 197555 224-229. (doi:10.1172/JCI107925)

22 Escobar-Morreale HF, Obregón MJ, Escobar del Rey F \& Morreale de Escobar G. Replacement therapy for hypothyroidism with thyroxine alone does not ensure euthyroidism in all tissues, as studied in thyroidectomized rats. Journal of Clinical Investigation 199596 2828-2838. (doi:10.1172/JCI118353)

23 Alevizaki M, Mantzou E, Cimponeriu AT, Alevizaki CC \& Koutras DA. TSH may not be a good marker for adequate thyroid hormone replacement therapy. Wiener Klinische Wochenschrift 2005117 636-640. (doi:10.1007/s00508-005-0421-0)

24 Surks MI, Ortiz E, Daniels GH, Sawin CT, Col NF, Cobin RH, Franklyn JA, Hershman JM, Burman KD, Denke MA et al. Subclinical thyroid disease: scientific review and guidelines for diagnosis and management. Journal of the American Medical Association 2004291 228-238. (doi:10.1001/jama.291.2.228)

25 Biondi B. How could we improve the increased cardiovascular mortality in patients with overt and subclinical hyperthyroidism. European Journal of Endocrinology/European Federation of Endocrine Societies 2012 167 295-299. (doi:10.1530/EJE-12-0585)

26 Wennlund A. Variation in serum levels of $\mathrm{T}_{3}, \mathrm{~T}_{4}, \mathrm{FT}_{4}$ and TSH during thyroxine replacement therapy. Acta Endocrinologica 1986113 47-49. (doi:10.1530/acta.0.1130047)

27 Sturgess I, Thomas SH, Pennell DJ, Mitchell D \& Croft DN. Diurnal variation in TSH and free thyroid hormones in patients on thyroxine replacement. Acta Endocrinologica 1989121 674-676. (doi:10.1530/ acta.0.1210674)

28 Jonklaas J, Bianco AC, Bauer AJ, Burman KD, Cappola AR, Celi FS, Cooper DS, Kim B, Peeters R, Rosenthal MS et al. Guidelines for the treatment of hypothyroidism. Thyroid 201424 1670-1751. (doi:10.1089/thy.2014.0028)

Received 6 February 2015

Revised version received 1 June 2015

Accepted 15 June 2015 